\title{
TEORIA E AÇÃO NO GT EDUCAÇÃO AMBIENTAL DA ANPED: PARTILHANDO ALGUMAS SUSPEITAS EPISTEMOLÓGICAS
}

\author{
Pedro Goergen ${ }^{1}$
}

Resumo: $\mathrm{O}$ autor faz uma análise dos trabalhos de pesquisa desenvolvidos pelos integrantes do GT 22 - Educação Ambiental da ANPEd. A análise concentra-se nos procedimentos metodológicos, nos conceitos de educação e ambiente, na relação entre crise ambiental e racionalidade moderna e na relação entre educação ambiental, gestão política e economia. O autor constata uma diversidade grande nos procedimentos metodológicos que orientam as pesquisas do GT e o recurso igualmente amplo a autores de diferentes orientações teóricas. Esse fato permite concluir que os trabalhos, em seu conjunto, ainda carecem de um debate teóricometodológico de fundo sobre, por exemplo, a ciência, seus sentidos e rumos. Fica evidente também a necessidade de definição mais acurada de conceitos básicos, tais como educação e ambiente, que perpassam todas as investigações. $\mathrm{Na}$ sequência, o autor analisa a temática da crise ambiental na perspectiva da narrativa logocêntrica e antropocêntrica moderna para entender melhor a postura agressiva do ser humano com relação ao meio ambiente. Com base nessas questões, são visualizados avanços possíveis para o campo da educação ambiental, em particular nos eixos da política e da economia.

Palavras-chave: educação ambiental, pesquisa, GT 22 da ANPEd.

Abstract: The author presents an analysis of research works developed by members of the Environmental Education Working Group (GT 22) of the ANPEd. This analysis focuses on methodological procedures, concepts of education and environment, the relationship between environmental crisis and modern rationality, and the relationship between environmental education, political administration and economy. The author identifies a large variety of methodological procedures guiding the working group researches, as well as the use of an equally large number of authors with different theoretical perspectives. This fact allows the conclusion that the works, as a whole, still lack a background theoretical and methodological debate on, for instance, science, its meanings and

${ }^{1}$ Professor titular da Universidade de Sorocaba (UNISO) e professor titular aposentado da UNICAMP. Contato: pedro.goergen@prof.uniso.br 
directions, whereupon the need for a more accurate definition of basic concepts such as education and environment, which appears in every investigation. Then the author analyses the environmental crisis theme from the perspective of modern logocentric and anthropocentric narrative aiming to achieve a better understanding of man's aggressive attitude toward nature. All these issues offer a perspective of possible advances in the environmental education field, particularly in relation to politics and economy.

Keywords: environmental education, research, Working Group 22 of ANPEd.

\section{Introdução}

A expressão 'partilhar suspeitas' foi incluída no título deste trabalho para, desde o início, deixar bem claro aos integrantes do GT Educação Ambiental que não me encontro aqui para emitir juízos de valor sobre o trabalho sistemático e especializado dos colegas. Aceitei o convite para fazer algumas considerações sobre os projetos de pesquisa do GT do ponto de vista epistemológico unicamente na suposição de que poderia trazer alguma contribuição para provocar um debate sobre os avanços dos trabalhos que vêm sendo realizados. Suponho que o olhar externo possa chamar a atenção para um ou outro aspecto da paisagem investigativa da educação ambiental que, eventualmente, passe despercebido aos especialistas da área.

Quando se lê um número tão grande de trabalhos para responder a um questionamento único - a avaliação dos projetos de pesquisa do ponto de vista epistemológico -, é forte a tentação de generalizar. Esse é um risco que desejo evitar a qualquer custo. De outra parte, também não me parece adequado fixar a atenção em projetos individuais. Tentarei, então, destacar alguns aspectos que julgo relevantes na perspectiva epistemológica, sem generalizar nem pontualizar, apenas com o objetivo de provocar um debate, eventualmente, proveitoso.

Antes de iniciar, gostaria de dizer, ainda, que foi para mim uma oportunidade única e rica de aprendizado poder familiarizar-me com as pesquisas que vêm sendo desenvolvidas sobre um tema que, evidentemente, me preocupa, mas a respeito do qual não tenho conhecimentos técnicos nem teóricos aprofundados. Como não domino a literatura da área, boa parte da bibliografia usada nos projetos me era desconhecida. O mesmo ocorre, pelo menos até certo grau de aprofundamento, com relação a alguns conceitos frequentemente usados. Isso naturalmente representa um grave handicap que, se for usado contra mim, poderá me derrubar da cadeira onde me encontro sentado.

Essa situação, é claro, me perturba e me faz quase arrepender-me de ter aceitado esta honrosa tarefa. Sou, portanto, culpado de não ter sabido resistir à insistente irresponsabilidade do Prof. Luiz Marcelo, que, acredito, de boa fé deu ouvidos a algumas pessoas que, não sei por quais motivos, assopraram meu nome em seus ouvidos. Mesmo assim, e jocosidades à parte, consola-me a 
esperança de que o olhar distanciado e não especializado possa, talvez, reconhecer da floresta aspectos que, quem sabe, escapam aos que nela vivem.

Devo observar, de início, que os colegas Martha Tristão e Luiz Marcelo de Carvalho já fizeram uma primeira análise de parte dos projetos, ou seja, daqueles que estão sendo publicados no número especial da Revista Educação e Ambiente, volume 14, número 2. Esse estudo segue, num primeiro momento, a trilha da análise do conteúdo da linguagem, trabalhando palavras e seus significados ou sentidos e, depois, interpretando a confluência discursiva dessas produções na configuração do campo epistemológico da educação ambiental.

$\mathrm{Da}$ análise dos colegas, gostaria de destacar a ideia de campo semântico, emprestada de Hugo Assmann, o qual se constitui de uma teia de palavras que, no seu conjunto, representa um espaço de sentidos, configurando a ambiência discursiva do sujeito que fala ou escreve. Digo isso para assinalar que esse conceito permeia as observações que adiante farei a respeito do rigor conceitual e da metodologia. Interessante atentar para a observação da Profa. Martha de que as comunidades muitas vezes estão apenas mais ou menos conscientes desse ambiente que empresta sentido aos seus discursos.

No texto, os colegas informam que a maioria dos projetos nasce vinculada a ações de intervenção direta na realidade, ou seja, não estavam inicialmente envolvidos com a produção de conhecimento. Surgem de projetos de formação inicial e continuada, de formação de educadores ambientais ou, ainda, de intervenções extensionistas, no sentido político ou prático. $\mathrm{Na}$ minha leitura, pude confirmar a persistência dessa duplicidade de perspectivas, tanto da intenção política de formar quanto do desenvolvimento de investigações.

Se, de um lado, boa parte se preocupa mais com a solução de problemas ambientais, priorizando a intervenção, de outro, busca-se investigar com a intenção de facultar aos sujeitos percepção e desvelamento das relações de poder. Nesse sentido, percebe-se em todos a ideia, subentendida ou explícita, de possibilitar a passagem do comportamento individual para práticas sociais coletivas, favoráveis à preservação do meio ambiente. Falando mais ao sujeito ou diretamente ao coletivo, nota-se que a maioria almeja o resgate do espaço público como estratégia para a construção de uma nova visão de mundo e uma nova relação com o mundo.

De resto, é importante, ainda, ressaltar o interessante levantamento dos objetivos, temas, métodos e preferências ideológicas presentes nos vários projetos de pesquisa. Considerando, então, que esse trabalho já foi realizado, vou orientar minhas observações em outra direção, menos diagnóstica e mais prospectiva. Explico: gostaria de destacar alguns pontos que chamo aqui de carências ou ausências e que, a meu ver, mereceriam mais espaço futuramente.

Tais apontamentos de modo algum desmerecem o trabalho que vem sendo realizado até o momento. Ao contrário, o engajamento e a riqueza dos projetos analisados são, sem dúvida, contribuições importantes para o avanço da educação ambiental no país. Apesar dos graves problemas ambientais que ainda 
enfrentamos, devem-se destacar os avanços alcançados nas últimas décadas, em especial em termos da formação de uma nova consciência ambiental. O mérito certamente é de muitos e, em boa medida, também dos integrantes do Grupo de Trabalho 22 da ANPEd.

Afinal, os primeiros sinais de alarme dados pelos cientistas e estudiosos dos problemas ambientais surgiram apenas em 1968 com o Relatório do Clube de Roma (MEADOWS ET AL., 1978) e a seguir, com a Conferência de Estocolmo Sobre o Meio Ambiente Humano (1972) e a Conferência Intergovernamental sobre Educaşão Ambiental de Tbilisi, na Geórgia (1977). Para nós brasileiros, a Conferência Rio-92 e a Agenda 21 deram início a um amplo processo de conscientização a respeito do valor da natureza e do sentido da produção do conhecimento.

No entanto, há dez anos, Leff $(2003$, p. 1) escreveu que "a este processo tem faltado uma reflexão sobre os fundamentos do saber ambiental e suas implicações nas práticas educativas para fundamentar uma pedagogia ambiental". Hoje, as múltiplas iniciativas e projetos de educação ambiental nos diferentes níveis de educação formal e informal em distintos setores da população permitem vislumbrar uma nítida tendência de avanço, e os trabalhos que vêm sendo desenvolvidos pelo GT Educação Ambiental são parte importante desse processo.

A julgar pelas datas de criação dos vários grupos de trabalho, foi nesse contexto que aconteceu o engajamento da academia, conforme testemunha a própria criação do GT Educação Ambiental na ANPEd. Aos poucos, ganha espaço e corpo uma reflexão mais ampla e sistemática sobre esse tema, embora ainda não alcance a repercussão desejada junto à população, nem junto aos setores políticos, gestores empresariais, produtores agrícolas ou responsáveis pela educação. Em geral, ao discurso a respeito da gravidade dos problemas ambientais, ouvido em todas as partes, não correspondem ações concretas para melhorar a situação. Em boa medida, o discurso ambientalista, em especial aquele veiculado por empresas, encontra-se atrelado a estratégias de marketing, que mais visam incrementar vantagens econômicas que zelar pelo meio ambiente. Quero, portanto, dizer, com todas as palavras, que é elogiável o trabalho realizado pelo GT em prol da conscientização dos problemas ambientais que necessitam ser enfrentados para se garantir um estado de bemestar da sociedade de hoje e de amanhã.

Isso posto, gostaria de fazer alguns comentários a respeito de certos aspectos que, a meu juízo, poderiam ser incluídos na agenda dos grupos. Ao longo da leitura dos projetos e da bibliografia da qual me apropriei, foram surgindo vários temas que poderiam ser aqui comentados, tais como: educação ambiental e currículo; educação ambiental na correlação local/global; educação ambiental e formação ética; educação ambiental e cultura; educação ambiental e política, democracia e cidadania, entre tantos outros. O limite de espaço e tempo, no entanto, impõe algumas escolhas que recaem sobre os seguintes pontos: 1) os procedimentos teórico-metodológicos; 2) o conceito de educação; 3) educação 
ambiental e a crise da racionalidade moderna; 4) educação ambiental e gestão política e 5) educação ambiental e pragmatismo econômico. Minhas observações pautam-se por conceitos como debate, discussão e diálogo, derivados do campo teórico da teoria crítica, no recorte hermenêutico de autores como Adorno, Horkheimer, Habermas e Freire.

\section{Os procedimentos teórico-metodológicos}

Certamente, estarei sendo repetitivo se disser que fica bastante evidente a diversidade de orientações teóricas subjacentes tanto aos projetos individuais quanto aos coletivos. Em termos de tendências gerais, registra-se certa polarização, ora mais rigorosa, ora mais solta, em torno de duas posturas teóricometodológicas que, de forma talvez imprópria e ciente das múltiplas nuances e diferenças, me atrevo a chamar de histórico-críticas e pós-modernas. Isso, na verdade, é apenas uma constatação, uma vez que, embora haja posicionamentos mais herméticos a favor de uma ou de outra orientação, trata-se de uma questão insolúvel no contexto do Grupo de Trabalho. Digo isso porque o tema envolve um debate histórico de grande envergadura e múltiplas implicações que vêm sendo conduzidas no âmbito da filosofia e da epistemologia, ainda sem solução. Não é este o momento adequado para tratar dessa questão implícita aos projetos de pesquisa e, certamente, objeto de debate em outros momentos das atividades do GT, a exemplo do que ocorre em outros GTs, como é o caso do de Filosofia da Educação, ao qual pertenço.

Quando hoje se fala em meio ambiente, logo se apresentam os temas da complexidade e diversidade como elementos necessários a uma estratégia racional que pretenda dar conta de um mundo em que se articulam conhecimento, ciência e tecnologia com natureza, sociedade e cultura. A complexidade do ser, do conhecimento, das identidades, da linguagem, das interpretações, das culturas, da alteridade, dos valores e dos sentidos se espelha nos discursos e procedimentos investigativos heterogêneos e formas de investigação que fazem frente ao projeto unitário da ciência moderna.

Se tomarmos como ponto de partida a tese de Morin e Le Moigne (2000) sobre o pensamento complexo, hoje assumida por muitos autores, veremos que também a educação ambiental tende a inserir-se na perspectiva de um multiculturalismo crítico. A esse conjunto de múltiplas faces contrapõem-se métodos mais tradicionais que postulam verdades comuns e universais. De fato, esse cenário investigativo representa um universo polissêmico de vozes e caminhos que seguem paralelos.

Basta um rápido olhar sobre os projetos de investigação para identificar procedimentos metodológicos tais como: fenomenológico, hermenêutico, transdisciplinar, construtivista, estruturalista, pós-estruturalista, sociocrítico, crítico-dialético, pós-moderno, qualitativo, análise do discurso, pesquisa-ação, 
pesquisa participante, multirreferencial, existencial, etnográfico. E autores como: Marx, Durkheim, Dewey, Weber, Latour, Adorno, Horkheimer, Certeau, Guattari, Moscovici, Vattimo, Castoriadis, Ardoino, Barbier, Morin, Freire, Merleau-Ponty, Bourdieu, Cordas, Hall, Sousa Santos, Prigogine, Sato, Carvalho, Tristão e Reigota.

No interior de um dos grupos e com relação apenas aos projetos ali desenvolvidos faz-se referência às diferentes orientações metodológicas, concluindo-se que

poderíamos então dizer que, a despeito dessas diferenças, constatamos um rol de princípios que são comuns e partilhados por todas/os no nosso fazer acadêmico, como: a produção coletiva e colaborativa de conhecimentos signifiativos; a valorização de processos educativos participativos e democráticos; a preocupação com explicitação e questionamentos acerca dos valores éticos e estéticos que informam o agir humano; o diálogo de saberes e as abordagens transdisciplinares; a diversidade e a sustentabilidade como valor e princípio para a manutenção da vida e da resiliência dos sistemas de vida (humanos e nãohumanos [sic]); a equidade, justiça social, solidariedade, o diálogo como condição fundante de nossa práxis.

Entendo que essa passagem revela a percepção de uma carência em termos de um debate epistemológico de fundo envolvendo a questão da ciência, de seus sentidos e rumos. Trata-se de um tema, diria, veladamente presente em quase todos os projetos e que não pode ser absorvido com a rápida menção a certos valores ou posturas comuns fundados no enfrentamento ao modelo da racionalidade dualista e instrumental moderno. Leff (2003) não me deixa sozinho com o entendimento de que esse é um tema absolutamente central à reflexão ambiental e precisa ser, portanto, devidamente abordado:

A problemática ambiental, mais que uma crise ecológica, é um questionamento do pensamento e do entendimento, da ontologia e da epistemologia com as que a civilização ocidental tem compreendido o ser, os entes e as coisas; da ciência e da razão tecnológica mediante as quais tem sido dominado e economicizado o mundo moderno (LEFF, 2003, p. 11).

Num dos projetos aparece de modo muito explícito o reconhecimento dessa carência de um debate epistemológico mais sistemático e aprofundado:

A experiência das pesquisadoras, em suas atividades docentes articuladas à pesquisa, mostra que a problematização da visão de ciência é um processo importante que, necessariamente, precisa perpassar a constituição de um pesquisador educador ambiental. Tal constatação tem fundamento na tese de que, sem esta problematização, o que ocorre é a assunção de pressupostos teóricos - ontológicos, epistemológicos, metodológicos - muitas vezes 
incoerentes entre o que está escrito nos relatórios em termos de referencial e as ações desenvolvidas ao longo da pesquisa.

De fato, como afirmam González Gaudiano e Meira Cortea (2009, p. 8),

o campo da educação ambiental é polidiscursivo. Nele convergem muitas teorias e concepções tanto sobre o educativo como sobre o ambiental, desde os enfoques pedagógicos mais instrumentais até os mais críticos com um amplo espectro de posturas frente à problemática ambiental, que vão desde a ecologia profunda até a ecologia social.

$\mathrm{O}$ que de um lado parece concernente ao contexto dos olhares polissêmicos, inerentes ao cenário epistêmico contemporâneo dos que observam e estudam os complexos fenômenos sócio-históricos do mundo atual, de outro revela uma confortável e pouco produtiva indiferença. Não se trata aqui de sugerir um monismo teórico-metodológico, mas de estimular o debate entre as distintas opções que não são indiferentes entre si, até porque seus objetivos finais representam modelos diferentes de sociedade. Mesmo sendo verdade que as múltiplas possibilidades de caminhos metodológicos permitem a livre expressão da criatividade dos pesquisadores e dos grupos implicados, é preciso estar atento para o risco da acomodação subliminar à aparente tolerância epistêmica.

O discurso conciliador é, na maioria das vezes, um falso discurso entre surdos. Quando os posicionamentos teórico-metodológicos assumem características de profissões de fé, postas como se fossem de foro íntimo, há uma conivência com o monólogo estéril inter pares que, ao contrário de dar conta da complexidade e diversidade, não contribui para a compreensão aprofundada, ainda que polimorfa, dos problemas ambientais. Evitando o debate e a conversa efetiva, varrem-se para debaixo do tapete as diferenças e perde-se a oportunidade de desvelar as contradições que, inconciliáveis ou não, portam consigo, como já disse, não só divergências lógicas mas também modelos socioeconômicos distintos.

Minha intenção é colocar em discussão um aspecto desse tema maior da orientação metodológica ou, como preferem outros, do referencial teórico, que, na falta de melhor termo, chamo de operacional. Ficou-me a impressão de que a opção teórico-metodológica assume, em boa parte dos projetos, uma característica operacional, ou seja, comunica-se ao leitor que será seguido este ou aquele referencial teórico sem um aprofundamento maior a respeito da consistência, da pertinência e também das implicações epistêmico-políticas da opção assumida. Reconheço que essa impressão carece de uma fundamentação mais consistente com base no desenvolvimento dos projetos, mas, mesmo assim, gostaria de levantar a pergunta se não se incorre num certo dogmatismo dos referenciais teóricos.

Do ponto de vista crítico, é preciso que, no contexto da investigação acadêmica, os inúmeros projetos parciais coparticipem, sem perder sua 
especificidade, do debate teórico-metodológico mais amplo. Do contrário, ainda que não percam de todo seu sentido local e relevância para a vida quotidiana, tais iniciativas perdem seu potencial transformador do cenário político-econômico maior. Dito de forma um pouco provocadora, os pequenos gestos que se esgotam em si mesmos parecem apostar na correção dos pequenos barulhos do trem da história que se movimenta rumo à catástrofe sem, no entanto, interferir em seu rumo.

Apesar de todos esses estudos e projetos estarem reunidos no âmbito de um GT da ANPEd, é ainda incipiente um debate aberto entre as diferentes abordagens investigativas sobre a construção e acúmulo de conhecimentos com densidade epistêmica suficiente para interferir no grande debate que vem sendo travado na sociedade sobre os temas do meio ambiente. Penso que seria possível avançar na construção disso que chamo de densidade epistêmica rompendo-se, inclusive, com a tendência monológica e individualista, que, em minha opinião, compromete o conjunto das atividades na ANPEd.

\section{O conceito de educação}

O próprio nome 'Educação Ambiental' revela o objetivo básico do conjunto de projetos que integram o GT: relacionar o tema do meio ambiente com educação. O pressuposto dessa relação é que a melhoria das deterioradas condições ambientais necessita da reeducação das pessoas porque só assim elas podem conscientizar-se da gravidade da situação e repensar seus comportamentos e atitudes frente à natureza. Esse me parece ser o sentido fundamental de todos os projetos.

Do ponto de vista epistemológico, o primeiro passo, comum a todos os grupos, seria o esclarecimento dos conceitos-chave, educação e ambiente. Efetivamente, na maioria dos projetos, nota-se a preocupação com a elucidação do termo 'ambiente', a ênfase em sua abrangência holística frente a conceitos como 'natureza' ou 'ecologia', ainda ligados à tradição dualista cartesiana entre o ser humano e seu entorno natural. Fica bastante claro como o conceito meio ambiente se conecta às questões do conhecimento, do poder, da sociedade, do tempo e da ética e como se constitui nessas relações como espaço próprio e único de reflexão e investigação. $\mathrm{O}$ mesmo, no entanto, parece não ocorrer com o conceito de educação, embora se saiba de seus múltiplos e variados sentidos.

Se me permitem regredir um pouco no tempo, gostaria de recordar a Carta de Belgrado de 1975 e lembrar os seis objetivos que foram definidos nesse encontro para a educação ambiental. São eles: conscientização, conhecimento, comportamento, competência, capacidade de avaliação e participação, assim definidos:

- Conscientização: levar os indivíduos e grupos associados a tomarem consciência do meio ambiente global e de problemas conexos e de se mostrarem sensíveis aos mesmos; 
- Conhecimento: levar os indivíduos e os grupos a adquirirem uma compreensão essencial do meio ambiente global, dos problemas a ele ligados, bem como do papel e lugar da responsabilidade crítica do ser humano;

- Comportamento: levar os indivíduos e os grupos a assimilarem o sentido dos valores sociais, o sentimento profundo de interesse pelo meio ambiente e a vontade de contribuir para a sua proteção e qualidade;

- Competência: levar os indivíduos e grupos a adquirirem a competência necessária à solução dos problemas, reconhecendo, como primeiro passo, que nem todos têm a capacidade técnica para resolver os desafios ambientais;

- Capacidade de avaliação: levar os indivíduos e grupos a avaliarem medidas e programas relacionados ao meio ambiente, em função dos fatores de ordem ecológica, política, econômica, social, estética e educativa;

- Participação: levar os indivíduos e grupos a perceberem suas responsabilidades e necessidades de ação imediata para a solução dos problemas ambientais.

Levar os indivíduos e grupos a tomarem consciência do meio ambiente com seus problemas, a compreenderem o meio ambiente no contexto global, a assimilarem o sentido dos valores sociais, a adquirirem a competência para a solução dos problemas ambientais, a avaliarem medidas e programas relacionados ao meio ambiente e a perceberem e assumirem suas responsabilidades na solução de problemas ambientais representa faces de um conceito que remete a um novo modelo de educação, muito distinto daquele que se coloca a serviço da razão dominadora e exploradora, subjacente à narrativa moderna de progresso, baseado na fé incondicional no potencial da ciência e tecnologia. Estão em jogo aí, na formulação de Adorno (1995, p. 139), a questão de o que é e a questão de para que é a educação.

Sem esse aprofundamento conceitual, o sentido da educação permanece ambivalente, uma vez que não se sabe a serviço de quem ela se encontra. Esse é um ponto de extrema relevância, já que a criação da autoconsciência ambiental e a mudança do comportamento dos sujeitos estão diretamente atreladas ao processo de produção de um novo conceito de educação que não seja conivente com o modelo logocêntrico da racionalidade econômica, científica e instrumental que objetaliza o mundo e domina/explora a natureza.

O que importa a este GT é descobrir o recorte epistêmico no qual e a partir do qual se podem oferecer intervenções propositivas em termos de desenvolvimento sustentável. Imagino que esse recorte seja o da educação e, por isso, é necessário deixar muito claro o que se entende por educação, o que, por sua vez, implica redefinir o significado e a função da atividade científica. 
A educação ambiental deve visar as questões formativas essenciais do ser humano em sua integralidade e não se perder em questões específicas do contexto ambiental. Quando se toma o conceito de educação em sua plenitude, isto é, em seu sentido de formação, pode-se dizer que não existe educação parcial deste ou daquele aspecto da personalidade. A consciência à qual a educação ambiental deve levar não é propriamente a consciência das questões ambientais, por mais importantes que sejam, mas uma consciência das pessoas acerca de si mesmas, do sentido de sua vida no contexto do ambiente em que vivem. É isso o que Adorno (1995, p. 121) chama de "inflexão em direção ao sujeito". Sujeito, evidentemente, não se entende aqui no sentido dualista cartesiano, mas no sentido de persona com a conotação heideggeriana holística de ser-no-mundo. Nisso radica o caráter transdisciplinar da educação ambiental.

Estas considerações me levam a ponderar que o conceito de educação, que tem assumido múltiplos sentidos e nuances ao longo das últimas décadas e, sobretudo, tem sido aplicado a um modelo de educação instrumental, exige um aprofundamento para que fique claro seu uso no contexto da educação ambiental. De minha parte, acredito que seria enriquecedor explorar a educação como formação (Bildung). Formação, diferentemente do sentido generalizado de educação, inclui uma forte conotação ética e estética e visa o desenvolvimento integral e equilibrado do potencial da personalidade (FLICKINGER, 2010, p. 125).

Hoje a educação está focada no trabalho, na habilitação profissional dos indivíduos para o acesso ao mercado. Profissionalização se conecta com economização e, portanto, desacoplamento do ideal da Bildung enquanto formação do homem integral, livre e autônomo. A educação profissional do ser humano é a qualificação não por ele e para ele, mas para as necessidades e exigências do mercado, a cujas regras ele necessariamente deve adaptar-se. $\mathrm{Na}$ esteira dessa tradição, Adorno (1995, p. 141) entende por educação uma "consciência verdadeira", uma exigência política.

Esse conceito de educação, que se refere ao processo de livrar a consciência do peso imensurável do existente e está focado na pessoa como um todo, nas suas dimensões epistêmica, ética e estética, faz frente à concepção contemporânea de educação como aquisição de informações, de conhecimentos e habilidades; faz frente também à educação instrumental fixada na utilidade material e econômica; faz frente, finalmente, ao vazio ético e à falta de valores, reconhecidamente um dos grandes dilemas da educação ambiental.

Em resumo, o que estou sugerindo é uma reflexão aprofundada sobre o conceito e os sentidos de educação, bem como sobre as teorias educacionais que, veladamente, informam as pesquisas do GT Educação Ambiental, ou seja, sobre os padrões de conhecimento e educação subliminarmente normalizados nesse campo do saber. Talvez assim se tornem, de algum modo, claros os descaminhos da educação que contribuíram para os riscos ambientais que hoje nos ameaçam 
de receber, sorrateiramente, pela porta dos fundos o que expulsamos pela porta da frente.

\section{Educação ambiental e a crise da racionalidade moderna}

O terceiro ponto que gostaria de trazer à discussão é de natureza estritamente epistemológica e se refere ao modelo de racionalidade desenvolvido a partir da modernidade. Todos sabem que o texto consagrado sobre essa temática é a Dialética do esclarecimento, de Adorno e Horkheimer. No capítulo sobre o conceito de esclarecimento, os autores escrevem: “(...) o esclarecimento tem perseguido sempre o objetivo de livrar os homens do medo e de investi-los na posição de senhores. Mas a terra totalmente esclarecida resplandece sob o signo de uma calamidade triunfal" (ADORNO; HORKHEIMER,1985, p. 19). O projeto de desencantar o mundo e dominar a natureza é, portanto, por assim dizer, conatural com a própria civilização. Pelo entendimento, o ser humano quer vencer a superstição e o medo diante da natureza, que o assusta e ameaça.

Esse é originariamente um projeto de liberdade e poder, dois objetivos que pressupõem o desentranhamento e o distanciamento entre o homem e a natureza. Essa luta pelo domínio sempre esbarrou nas limitações do homem. Nem os deuses mitológicos nem as entidades metafísicas ou mesmo o Deus pai todo-poderoso libertavam-no da condição de ganhar a vida no suor do seu rosto, como estava escrito no texto sagrado.

A grande reviravolta aconteceu com o surgimento da ciência, especialmente da física e da matemática, que conseguiram desvendar as regularidades da natureza e expressá-las em fórmulas. A natureza apresenta-se agora como um texto que pode ser lido matematicamente, dominado e usado. O conhecimento da lei, o cálculo e a previsão abrem caminho para a operação conduzida pela ideia de proveito, de utilidade.

Com isso, o pensamento torna-se autônomo, subjetivo em face às coisas, objetivas. A sujeição do mundo e da natureza, pela descoberta de suas regularidades, distanciou o sujeito em relação ao objeto, separou o conceito da coisa. Com a eliminação do desconhecido do não dominado, o homem presumiu livrar-se do medo. Esse impulso determina o movimento do esclarecimento que alcançou um novo patamar com o que Nietzsche chamou de morte de Deus e Weber, de desencantamento do mundo. À medida que o ser começa a ser pensado como ente, abre-se o espaço para a racionalidade científica e instrumental/positivista, que permite ao homem assumir o domínio e o controle sobre a ordem coisificada e fragmentada.

Com o avançar do esclarecimento, o pensamento confunde-se com a matemática e o mundo matematizado, com a verdade. $\mathrm{Na}$ expressão de Adorno e Horkheimer (1985, p. 37), "o pensar reifica-se num processo automático e autônomo, emulando a máquina que ele próprio produz para que ela possa finalmente substituí-lo". Substituído o homem, o pensamento deixa de pensar 
em si mesmo e se transforma em instrumento para "assumir o imperativo de comandar a práxis". Apesar da "magistratura da razão esclarecida", o pensamento fica preso à imediaticidade factual que passa a ter a última palavra. Assim, "a dominação universal da natureza volta-se contra o próprio ser pensante", privando-o de sua subjetividade e transformando-o num elemento da aparelhagem econômica. Por isso, mesmo preso à práxis, o ser humano perde a capacidade de ouvir o imediato, perde a sensibilidade para os riscos que sua intervenção na natureza provocam.

É esse mesmo projeto epistêmico o que funda a ideia do crescimento e da produção sem limites, da lógica da verdade absoluta, do pensamento unitário e da ciência objetiva, do domínio, do controle e da gestão racional do mundo enquanto objeto externo, do progresso ilimitado como parusia e salvação. Essa lógica incorpora os limites, as incertezas e os riscos como condições intrínsecas ao seu procedimento. Aficionado por essa ideia de progresso, o ser humano é acometido por grave cegueira em relação àquilo e àqueles que vão ficando à beira da estrada.

O conhecimento, o domínio e a exploração da natureza fizeram o homem sucumbir à própria natureza, que, ferida, se vinga. Por isso, faz sentido dizer que a crise ambiental do nosso tempo é uma crise do conhecimento. A crise ambiental problematiza a racionalidade científica; é o reflexo da intervenção do pensamento, na forma de ciência e tecnologia, no mundo; é o sinal de que o mundo dominado e planejado chega ao seu limite.

Desde o momento em que criou condições para assumir as rédeas de sua história, o homem passou a acreditar cegamente nas vantagens do progresso e do desenvolvimento, sem olhar para as consequências negativas e destrutivas dessa opção histórica. Foram necessários três séculos e a ocorrência de ameaças assustadoras para convergirem na memória os rastros de agressão que o projeto moderno foi deixando pelo caminho.

A crise ambiental, que ora vivemos, nos leva a questionar o projeto epistemológico, orgulhoso de ter descoberto o mapa da mina do progresso humano; nos leva a questionar, a partir de seus resultados, as ideias absolutas e universais da razão ordenadora e dominadora; nos leva a questionar a divisão entre o sujeito e o objeto, entre o homem e a natureza, responsável por fundar a narrativa científico-tecnológica moderna, sobre cujo chão floresce a ciência econômica, portadora do ideal mecanicista das leis do mercado, da economização do mundo político e do próprio ser humano.

A dicotomia entre o ser humano e a natureza, ou seja, a visão antropocêntrica, reporta-se diretamente ao modelo de racionalidade, de conhecimento e tecnologia desenvolvido a partir da modernidade e que possibilitou a intervenção na natureza, gerando impactos que hoje esgotam os recursos naturais e ameaçam a vida de muitas espécies animais e da própria humanidade. 
Estas considerações, inspiradas na Dialética do esclarecimento, de Adorno e Horkheimer (1985), têm o sentido de sugerir a busca dos fundamentos epistemológicos da crise ambiental que hoje vivemos. De um lado, o retorno às origens permite reconhecer a natureza fideísta do projeto moderno que imaginou alcançar o progresso com um modelo de ciência e tecnologia que sacrifica a natureza e o ser humano; de outro, nos indica o caminho, talvez único, de escapar da morte anunciada pela iminente catástrofe ambiental: a reforma do pensamento e a construção de uma racionalidade ambiental que "integre os potenciais da natureza, os valores humanos e as identidades culturais em práticas produtivas sustentáveis" (LEFF, 2003, p. 25).

No âmago da moderna narrativa logocêntrica de compreensão, de ordenamento, domínio e controle, encontra-se o impulso de desestruturação e desequilíbrio ambiental. E é no âmago dessa narrativa epistêmica que podemos encontrar os impulsos de transformação e superação da crise: a reforma do pensamento e a construção de uma nova racionalidade ambiental (LEFF, 2003), conjugadas à transição para uma nova ordem social. Do impulso advindo das externalidades da racionalidade dominante pode emergir um ambiente epistêmico que trate de impulsionar formas diferentes de convivência com a natureza no campo conflituoso do desenvolvimento sustentável, rompendo a dicotomia entre sujeito e objeto e a lógica da razão instrumental.

A crise ambiental, nesses termos, pode ser interpretada, na sua raiz, como uma crise da razão, e não propriamente como uma crise ecológica. A crise ecológica é apenas uma decorrência dessa dialética iluminista que Adorno e Horkheimer (1985) tão bem descreveram. Os problemas ambientais, segundo Leff (2003, p. 45), são fundamentalmente problemas do conhecimento. Esse é o portal que nos conduz a uma interpretação do sentido mais profundo da educação ambiental. A formação de uma nova consciência como elemento alavancador de uma nova postura ecológica depende exata e fundamentalmente de uma nova postura epistêmica. Por essas razões expostas, creio que o estudo e o debate da relação entre educação ambiental e racionalidade instrumental moderna são matriciais para o GT Educação Ambiental.

\section{Educação ambiental na dimensão política}

Os aspectos teórico-metodológicos e conceituais que comentei até o momento, de certo modo, fazem parte do circuito interno do trabalho de investigação. Nos dois pontos seguintes farei breve menção à interlocução com outros espaços de reflexão e ação, no caso, a política e a economia. Julgo essas duas dimensões - o rigor interno e diálogo externo - imprescindíveis para o trabalho investigativo que valoriza a integração e a transdisciplinaridade e pretende evitar a fragmentação e a especialização extremadas.

Senão todos, pelo menos boa parte dos projetos faz menção à transdisciplinaridade como um dos suportes indispensáveis à pesquisa na área. Talvez porque se trata de projetos acadêmicos, pareceu-me que o conceito 
'transdisciplinar' ainda ficou limitado à noção escolar de disciplina. Eu gostaria de sugerir a transgressão desses limites e a ampliação da articulação transdisciplinar com outros ambientes relativos à vida social-político-econômica, de maneira geral.

Com relação à política, os projetos destacam, repetidas vezes, a natureza política da educação ambiental. Efetivamente, educação ambiental não se restringe a intervenções isoladas nem apenas à educação de indivíduos ou comunidades para a consciência e atuação ecologicamente corretas. O próprio conceito 'ambiente' reinterpreta e rompe as fronteiras da relação homemnatureza. Reinterpreta no sentido de superar a disjunção cartesiana entre sujeito e objeto com o paradigma da complexidade que permite, no dizer de Morin e Le Moigne (2000, p. 67), "compreender o humano ao mesmo tempo em associação e em oposição à natureza" e rompe à medida que se abre para outras dimensões do humano, como a ética, a estética e a política.

Nesse sentido, são referência internacional as teses defendidas por Reigota (2009) (integrante deste GT) a respeito da natureza política da educação ambiental. Segundo o autor, a educação ambiental deve estar

comprometida com a ampliação da cidadania, da liberdade, da autonomia e da intervenção direta dos cidadãos e das cidadãs na busca de soluções e alternativas que permitam a convivência digna e voltada para o bem comum. (...) $\mathrm{O}$ que deve ser considerado prioritariamente na educação ambiental é a análise das relações políticas, econômicas, sociais e culturais entre a humanidade e a natureza e as relações entre os seres humanos, visando a superação dos mecanismos de controle e de dominação que impedem a participação livre, consciente e democrática de todos (REIGOTA, 2009, p. 13).

Essa educação política visa preparar os cidadãos/ãs comprometidos/as para a convivência respeitosa e digna entre as pessoas, as outras espécies biológicas e a própria natureza. Em vez do dualismo cartesiano, Reigota (2009) insiste na necessidade de uma 'nova aliança' entre os seres humanos e a natureza. Nos termos dessa aliança, a educação política deve ser criativa, inovadora e crítica. Criativa na busca de novas tecnologias e temáticas; inovadora ao relacionar conteúdos e temáticas ambientais às demais dimensões da vida cultural, ética, política e econômica; e crítica com relação aos dogmas científicos, religiosos, culturais, a favor do respeito a todas as formas de vida, da diferença e da promoção da igualdade.

A educação ambiental não visa, portanto, apenas transformar a consciência e as posturas individuais, mas formar cidadãos/ãs interessados/as em participar da definição e implementação de um novo ambiente político, econômico e social sustentável. Por essa razão, a educação ambiental é, essencialmente, uma educação política, ou seja, uma educação para a democracia.

Mesmo reconhecendo a postura transdisciplinar e a abertura para a dimensão política presentes nos projetos, parece-me que, no geral, ainda 
prevalece o enfoque disciplinar. Refiro-me ao olhar disciplinar educacional que, enquanto espaço não transgredido, alimenta uma velada e ilusória fé messiânica no seu potencial. Ora, já é consenso que na sociedade complexa, interdependente e globalizada nenhum ator isolado pode gerar um processo de transformação. Beck (2008, p. 26) escreve que "somos membros de uma 'comunidade de perigo mundial'. Os perigos já não são uma questão interna de cada país nem um país pode combatê-los sozinho".

Por maior que seja o entusiasmo e o empenho, a educação ambiental não terá o impacto esperado se não estiver articulada às demais dimensões da vida social, em particular à econômica e à política. Por isso, a imprescindível intervenção circunstanciada e concreta precisa conectar-se, permanentemente, com as outras dimensões da vida social para, conjuntamente, romper com o modelo político-econômico instrumental/explorador. Sobre essa relação incide, aliás, a postura crítica avocada por todos os projetos de pesquisa. Por isso, lembra Beck (2008, p. 22) que "a semântica do risco é hoje de especial atualidade e relevância tanto na linguagem da técnica, da economia, das ciências naturais como na da política".

Trata-se não só de conscientizar as pessoas para atuar na solução de problemas concretos já existentes e evitar novos mas de preparar os caminhos para um futuro sustentável. E essa preparação é, antes de tudo, a formação dos cidadãos/ãs do futuro. Só na complexidade do entrecruzamento de posições sociais, valores e ações divergentes e antagônicas surgem novas identidades individuais e coletivas, portadoras de um novo saber ambiental, de uma nova epistemologia "na qual se fundem conhecimentos, se projetam valores e internalizam saberes" (LEFF, 2003, p. 2).

Mas o futuro não depende apenas das decisões individuais ou comunitárias. Há atores privilegiados, como o Estado e o sistema econômico, que, se não se juntarem à luta comum, irão arruinar o futuro de todos. Das decisões do mercado depende o futuro de progresso ou de ruína. Os governos hoje obedecem aos mandados da chamada realpolitik, que impõe os interesses pragmáticos tanto do jogo político quanto da economia de mercado. De pouco adianta a formação de uma consciência individual a respeito do uso mesurado dos recursos naturais, do consumo ou da produção de dejetos se ela se estanca em si mesma. É necessária a formação de uma opinião e uma sociedade civil suficientemente fortes para pressionar os agentes políticos e econômicos. Seria, segundo Beck (2008, p. 101), "a união entre a sociedade civil e o Estado que significa o nascimento (...) de uma forma cosmopolita de estatalidade".

Em termos sistêmicos é, portanto, necessária uma consciência ambiental política capaz de conter a voracidade e a agressividade inerente ao sistema político-econômico. Isso implica a criação de uma nova mentalidade, de uma nova racionalidade. Por isso, a tarefa talvez mais importante da área de educação ambiental seja a formação de uma opinião pública, de um lado, sensível e aberta 
aos problemas ambientais, mas, de outro, disposta ao engajamento político. Creio ser a formação da opinião pública atuante o fator mais importante, tanto para o incremento de políticas públicas ambientais quanto para o avanço do ambientalismo corporativo. Em vista disso, no centro de toda a educação ambiental deve estar o conceito de educação política.

Feitos estes comentários sobre a natureza política da educação ambiental e constatada esta preocupação no interior do GT, gostaria apenas de chamar a atenção para este aspecto particular da política ambiental de Estado. Refiro-me às políticas públicas, ou seja, à atuação do Estado no que diz respeito à política ambiental. A política e o direito devem exercer sua função de controle e direção de que dispõem para superar essa dupla cara do progresso. Como se percebe, é um aspecto particular do caráter político da educação ambiental, mas do maior interesse para um projeto social sustentável para o futuro. O que me leva a destacar essa dimensão do político é a ambivalência que vejo na atuação do Estado, cujos representantes, ao mesmo tempo que manejam com maestria o discurso ambientalista, seguem profundamente comprometidos com o modelo socioeconômico neoliberal, responsável, em grande medida, pela persistência, geração e gravidade dos problemas ambientais. Nesse populismo, aliás, coincidem os representantes políticos e os dirigentes das grandes corporações empresariais. E, se isso não for mudado, sempre ficarão restritos os efeitos de todos os esforços a favor de um modelo sustentável de desenvolvimento.

\section{A educação ambiental e o pragmatismo econômico}

Gostaria agora de estender as considerações anteriores para o âmbito da economia. A mesma necessidade de relacionar as iniciativas ambientalistas circunstanciadas às políticas públicas contrárias à governança ambientalmente correta também se aplica à ontologia sistêmica da economia neoliberal. Se não considerarmos e questionarmos os tratores do sistema neoliberal que desfiguram, por definição, o ambiente por onde passam, continuaremos à retaguarda, respirando sua poeira e tentando reparar os estragos que fazem.

Se não dialogarmos de forma mais intensa e objetiva com a área econômica, uma série de temas da mais alta relevância ficarão excluídos da agenda dos debates. E, nesse caso, o debate se torna, por assim dizer, endemicamente soft, ou seja, perde a pregnância da vida real com as determinantes políticas e, sobretudo, econômicas, que, bem ou mal, existem e precisam ser levadas em conta, por mais contrárias que sejam às nossas próprias convicções. Também a pesquisa acadêmica precisa mover-se sempre no contexto do conhecido tripé da sustentabilidade: o econômico, o social e o ambiental.

Para fazer as observações a seguir, vou servir-me de duas publicações. A primeira, de 2005, de Beat Bürgenmeier, intitulada Economia no mundo sustentável, e a segunda, de 2010, de Ricardo Arnt, chamada O que os economistas pensam sobre a sustentabilidade. Enquanto o primeiro é um manual sobre o desenvolvimento 
sustentável do ponto de vista econômico, o segundo reúne entrevistas sobre a questão do crescimento econômico e meio ambiente com os mais destacados economistas brasileiros.

Quero chamar a atenção para a distância que existe entre os modelos de racionalidade propostos no contexto da educação ambiental e o modelo econômico dominante. Nota-se um claro descompasso entre o idealismo da educação ambiental e o pragmatismo da economia. Beck (2008, p. 64) é incisivo ao afirmar que 'talvez se possa falar de 'meio ambiente' em um contexto econômico particular, mas quando se trata da atividade econômica em sua totalidade o discurso se converte em função". Na educação ambiental se defende um modelo de racionalidade que ultrapassa os limites da razão técnico-científica instrumental e se abre para outras dimensões do humano, como a cultural, a política e a ética, ao passo que a racionalidade econômica se orienta, preponderantemente, para o crescimento econômico, admitindo como incontornáveis os efeitos negativos sobre o ambiente. Minha ponderação é que deve haver uma maior convergência, digamos, dialético-dialógica entre as teses da educação ambiental e o mundo da economia real.

No contexto do modelo econômico hegemônico, o crescimento é uma preocupação central de todos os países, uma vez que domina a conviç̧ão de que esse é o único caminho para o desenvolvimento social e econômico. No entanto, segundo Bürgenmeier (2005, p. 15), "a relação entre a poluição e o crescimento econômico é estreita, uma vez que exprime uma interação permanente entre as atividades humanas e o ambiente natural". Daí derivam perguntas a respeito do conceito de crescimento, da relação entre crescimento e degradação ambiental e, enfim, da necessidade ou não do crescimento.

As respostas a essas perguntas são muitas e polêmicas, suscitando sempre acirrados debates a respeito da natureza do crescimento (social ou puramente econômico), da medida do crescimento e, até mesmo, da necessidade ou não do crescimento. Por sua vez, cada um desses temas muda de figura quando se trata de países ricos, países em desenvolvimento ou países pobres. Além disso, as respostas a essas questões variam segundo se trata de um crescimento estritamente econômico ou de um crescimento que leva em conta os custos socioambientais decorrentes da poluição.

Os defensores da chamada curva de Kuznets são favoráveis ao atual modelo de crescimento, com o argumento de que as externalidades tendem a regredir com o avançar do crescimento. Já outros, como Georgescu-Roegen, defendem a ideia radical do decrescimento em função do esgotamento dos recursos naturais. Outros, ainda, apostam no gênio humano para desenvolver novas tecnologias capazes de neutralizar os efeitos negativos do crescimento.

Como se pode observar, o que está em debate é o legado do Iluminismo, da metanarrativa da ciência e tecnologia, do progresso infinito baseado na ideia dos recursos naturais inesgotáveis. Hoje as teses do crescimento zero ou do 
decrescimento são consenso de críticas. Não se vê, portanto, pelo menos até o momento, alternativa para o crescimento. Contudo, segundo Bürgenmeier (2005, p. 26),

apesar de a economia ser cada vez mais interpretada num espírito positivo, pelo fato de favorecer uma abordagem técnica e instrumental, ela interpela-nos sobre questões de fundo: qual a finalidade da atividade humana, qual o nível de bemestar que se procura atingir? A procura do crescimento, da produção e do consumo deve ser considerada como a única resposta?

Dessa constatação, que parece difundir-se cada vez mais no contexto da sociedade de risco (BECK, 2008), decorrem pelo menos três importantes inovações: a) o quadro jurídico que regula as atividades econômicas no que diz respeito ao direito ambiental está mudando; b) as externalidades começam a entrar no cálculo econômico dos preços finais dos produtos; e c) as desigualdades sociais globais repercutem nas reformas econômicas internacionais.

Talvez refletindo os distintos momentos vividos pelos países centrais e pelos países em desenvolvimento, essa visão de Bürgenmeier, um tanto otimista, é contrariada pela postura de importantes economistas brasileiros. No Brasil, o tema da proteção social só chegou com a Constituição de 1988. Mas, a despeito de sermos tardios, não se pode negar que temos feito progressos à medida que, aos poucos, parece difundir-se a ideia de que é preciso conservar e conversar. No entanto, segundo Belluzzo (2010, p. 158), "quando os economistas se põem a falar sobre questões ecológicas, eles não conseguem romper o círculo vicioso entre o uso dos recursos e a acumulação de capital". Por isso, "a sociedade avançou de forma contraditória, construindo a possibilidade de se desenvolver sem agredir a natureza, mas, ao mesmo tempo, tornando essa agressão cada vez mais dolorosa".

Por que ocorre isso? Porque essa é a forma de o capitalismo, interessado apenas no lucro, usar os recursos naturais. O capitalismo se orienta no lucro e para alcançar esse objetivo não mede consequências. Por isso, apesar dos sinais de conscientização, a economia capitalista e o movimento ambientalista continuam seguindo duas lógicas distintas e opostas. Sobre esse fundo epistêmico entende-se por que o economista Delfim Neto (2010, p. 23), ao ser perguntado se a capacidade de suporte [da natureza] não o preocupa, deu a seguinte resposta: "Eu me preocupo, mas o que posso fazer? Este futuro eu não vou viver". Sem querer generalizar, esse posicionamento espelha a atitude centrada no aqui e agora dos que, a qualquer preço, defendem o modelo econômico predatório. Embora não partilhem desse pragmatismo irresponsável, economistas de visão mais aberta não escondem as dificuldades de uma economia ambientalmente correta. Segundo Mercadante (2010, p. 198): 
O mais difícil é financiar a economia de baixo carbono. (...) Olhando o cenário, enfrentar as mudanças climáticas significa mais um custo relevante no orçamento, porque este esforço não é um custo marginal. O financiamento da economia de baixo carbono terá de perpassar todas as políticas públicas.

Perguntado por Arnt (2010) se "o desafio de construir uma economia de baixa emissão de carbono implica [u]ma mudança de paradigma no pensamento econômico", Mercadante (2010, p. 199) respondeu:

Implica [u]ma mudança completa. As categorias que formaram toda uma geração de economistas e administradores públicos estão superadas. Precisamos estudar com mais profundidade a relação entre economia, crescimento, preservação do meio ambiente e 'pegada ecológica', além de buscar uma reconversão produtiva que não seja só uma questão energética.

Essa constatação é vital porque nos leva a refletir sobre o caráter muitas vezes altruísta de nossas teses descomprometidas com a economia real. Por isso, esse tipo de discurso altruísta é estranho ao pragmatismo econômico. Mais importante é a economia se dar conta de que sem os cuidados ambientais crescem as dificuldades de comercialização dos seus produtos. Essas dificuldades sustentam-se diretamente na consciência da população, ou seja, na consciência praticada dos consumidores. Consciência praticada significa a disposição de repensar e mudar os comportamentos direta ou indiretamente prejudiciais ao meio ambiente. Aí se fecha o círculo entre o sistema econômico e o sistema educacional.

O homo oeconomicus precisa entender que a natureza tem um tempo diferente do ser humano. Sua história se conta em três bilhões e seiscentos milhões de anos. O homem apareceu nessa história nos últimos segundos. Tal como superou muitos outros problemas ao longo de sua história, a natureza, com a maior naturalidade, pode livrar-se do problema homem. Então, como diz Vianna (2010, p. 219), integrante da Comissão Brasileira na COP-15 em Copenhagen, 2009: "não se trata de nos arvorarmos em deuses onipotentes que cuidarão de Gaia, a mãe que está precisando de ajuda. Ela não precisa de ajuda; ela nos ignora. Se a gente encher muito o saco, ela se livra de nós”(...).

A economia, na medida em que representa a efetivação da racionalidade instrumental e científico-tecnológica e se encontra na raiz da relação patológica entre o ser humano e a natureza, constitui-se num elemento central de qualquer projeto de superação da crise ambiental. Em função disso, o tema da economia é também central a qualquer projeto de educação ambiental.

Por isso, é, de certo modo, surpreendente que os projetos que tive a oportunidade de ler façam referência, raras, bem raras vezes, ao contexto econômico neoliberal e, se bem observei, apenas uma única vez se fala, por exemplo, do assim chamado Consenso de Washington. Isso para não falar da 
ausência completa dos grandes agentes internacionais, como é o caso do Banco Mundial (BM), do Banco Interamericano de Desenvolvimento (BID) e do Fundo Monetário Internacional (FMI), que interferiram e ainda interferem nas políticas públicas de educação, sobretudo dos países em desenvolvimento, colocando-as na trilha dos interesses do capitalismo global, com tudo o que isso representa em termos de interferência no meio ambiente.

Este espinhoso assunto não se resolve com velhos jargões. É preciso não evitar o debate concreto e direto, no caso com os economistas, porque é ali, na ágora dos debates políticos, econômicos, culturais e éticos, que se geram as reais possibilidades de transformação. Do contrário, corre-se o risco de cair num ostracismo acadêmico sem real interferência revolucionária, como pressupõe a utopia subjacente às análises macrossociais.

\section{Conclusão}

A partir da leitura dos projetos de pesquisa do GT Educação Ambiental, tentei fazer algumas observações do ponto de vista epistemológico. Estas observações se limitam ao que pude inferir a partir de projetos de pesquisa, e não de relatórios de pesquisa. Corri, portanto o risco de anotar questões que, no decorrer das pesquisas, foram ou poderão vir a ser superadas. Além disso, volto a lembrar que falei de tendências gerais que podem estar mais presentes em alguns casos que em outros.

Dos cinco pontos que assinalei, os três primeiros se concentram sobre aspectos epistemológico-conceituais da educação ambiental e os dois últimos, sobre interfaces temáticas, a meu ver, relevantes para evitar o monólogo disciplinar e o altruísmo desconectado da realidade política e econômica.

Quanto ao primeiro ponto, referente aos procedimentos teóricometodológicos, destaquei que me pareceu perceptível certo dogmatismo na forma de enunciar os procedimentos metodológicos com base no argumento da autoridade de alguns autores, sem uma argumentação adequada a respeito dos procedimentos sugeridos na sua relação com o projeto investigado. De outro lado, do ponto de vista do conjunto dos projetos, senti a falta de um debate entre as diferentes posturas teórico-metodológicas diante de suas distintas implicações socioeconômicas.

No segundo item, fixei-me num aspecto especial já inerente ao primeiro: conceito de educação como parte do binômio 'educação ambiental'. Constatei uma preocupação coerente com relação à explicitação conceitual do termo 'ambiente', mas o mesmo não ocorre com relação ao conceito 'educação'. Por duas razões, parece-me importante que tal aclaramento seja feito: a) porque 'educação' é um conceito polissêmico, sendo empregado em muitos sentidos não só diferentes mas contraditórios; b) porque só o delineamento do termo 'educação' confere densidade conceitual epistêmica ao binômio 'educação ambiental'. 
Quanto ao terceiro passo, que trata da relação entre educação ambiental e a crise da racionalidade moderna, tentei argumentar que seria importante ambientar a crise ambiental na narrativa moderna do progresso científicotecnológico e da razão instrumental. Penso que a explicitação desses precedentes teórico-históricos tanto tornaria mais fácil compreender a dimensão epistêmica da educação ambiental quanto ajudaria a embasar historicamente alternativas de solução.

No penúltimo aspecto, a relação entre educação ambiental e gestão política, procurei argumentar a favor de uma aproximação dialógica mais estreita entre educação ambiental e política. Parto do ponto de vista de que não pode haver uma reversão da crise ambiental sem adequadas políticas públicas para o setor. O Estado, com todas as suas interferências, tanto na própria educação quanto na economia, é um agente indispensável para a recuperação do equilíbrio ambiental.

Por último, faço referência à educação ambiental e o pragmatismo econômico. Trata-se de um aspecto nevrálgico porque a economia exerce a função de braço executivo da razão instrumental. Enquanto não se convencer, mediante a pressão da opinião pública, o setor econômico a repensar a ideia de crescimento, dificilmente serão alcançados avanços na superação da crise ambiental. Por essas razões, é preciso intensificar o diálogo entre educação ambiental, política e economia.

\section{Referências}

ADORNO, Theodor. Educaşão e emancipação. Trad. Wolfgang Leo Maar. São Paulo: Paz e Terra, 1995.

ADORNO, Theodor; HORKHEIMER, Max. Dialética do esclarecimento. Trad. Guido A. de Almeida. Rio de Janeiro: Zahar, 1985.

ARNT, Ricardo. O que os economistas pensam sobre sustentabilidade. São Paulo: 34, 2010.

BECK, Ulrich. La sociedad del riesgo mundial - en busca de la seguridad perdida. Barcelona: Paidós, 2008.

BELLUZZO, Luiz Gonzaga. Entrevista. In: ARNT, Ricardo. O que os economistas pensam sobre sustentabilidade. São Paulo: 34, 2010.

BÜRGENMEIER, Beat. Economia do desenvolvimento sustentável. Trad. Ana André. Lisboa: Instituto Piaget, 2005.

FLICKINGER, Hans Georg. A caminho para uma pedagogia hermenêtica. Porto Alegre: manuscrito, 1910.

FUNTOWICZ, Silvio; DE MARCHI, Bruna. Ciencia posnormal, complejidad reflexiva y sustentabilidad. In: LEFF, Enrique (Coord.). La complejidad ambiental. 2. ed. México; Buenos Aires: Siglo Veintiuno, 2003. 
GONZÁLEZ GAUDIANO, Edgar; MEIRA CORTEA, Pablo. Educação, Comunicação e mudança climática. Trajectorias, v. 13, n. 29, jul-Dec, 2009, p. 6-38.

LEFF, Enrique (Coord.). La complejidad ambiental. 2. ed. México; Buenos Aires: Siglo Veintiuno, 2003.

MEADOWS, Dennis; MEADOWS, Donella; RANDERS, Jorgen; BEHRENS, William. Limites do Crescimento: Um Relatório para o Projeto do Clube de Roma sobre o Dilema da Humanidade. Trad. Ines M. F. Litto. São Paulo: Perspectiva, 1972.

MERCADANTE, Aloizio. Entrevista. In: ARNT, Ricardo. O que os economistas pensam sobre sustentabilidade. São Paulo: 34, 2010. p. 197-214.

MORIN, Edgar; LE MOIGNE, Jean-Louis, A inteligência da complexidade. Trad. Nurimar Maria Falci. São Paulo: Peirópolis, 2000.

NETO, Delfim. Entrevista. In: ARNT, Ricardo. O que os economistas pensam sobre sustentabilidade. São Paulo: 34, 2010.

REIGOTA, Marcos. O que é educação ambiental. São Paulo: Brasiliense, 2009.

VIANA, Sérgio Besserman. Entrevista. In: ARNT, Ricardo. O que os economistas pensam sobre sustentabilidade. São Paulo: 34, 2010. p. 215-234.

ZYLBERSZTAJN, David; LINS, Clarissa (Org.). Sustentabilidade e geração de valor: a transição para o século XXI. Rio de Janeiro: Elsevier, 2010.

Artigo recebido em 20/08/2010 - - aprovado em 17/12/2010 